\title{
Haematological and Serum Biomarker Responses in Heteropneustes fossilis Exposed to Bisphenol A
}

\author{
Bhawna Srivastava and P. B. Reddy $* \dagger$ \\ Department of Zoology, DAV College, Kanpur, U.P., India \\ *PG Department of Zoology, Govt. Art and Science College, Ratlam, M.P., India \\ $\dagger$ Corresponding author: P. B. Reddy; reddysirr@gmail.com
}

Nat. Env. \& Poll. Tech. Website: www.neptjournal.com

Received: 08-01-2020

Revised: $17-02-2020$

Accepted: 09-03-2020

Key Words:

Biomarkers

BPA

Heteropneustes fossilis

Haematology

Serum biochemistry

\begin{abstract}
The present investigation was carried out for 21 days to explore the sub-lethal toxicity of bisphenol A (BPA) of concentration $0.714,1.428$ and $2.142 \mathrm{mg} / \mathrm{L}\left(1 / 10,1 / 20\right.$ and $1 / 30 \%$ of $\left.96 \mathrm{~h} \mathrm{LC}_{50}\right)$ on haematological and serum biochemical parameters of Heteropneustes fossilis. Routine haematological parameters like total erythrocyte count (TEC), total leukocyte count (TLC), haemoglobin content $(\mathrm{Hb})$, haematocrit $(\mathrm{Hct})$, erythrocyte indices, total serum protein, alanine aminotransferase (ALT), and aspartate aminotransferase (AST), albumin, globulin, uric acid, and creatinine were examined as toxicological endpoints. The findings of this study revealed that BPA had a negative effect on both the haematological and serum biochemical parameters of Heteropneustes fossilis. The study revealed a significant decrease in red blood cell count, haemoglobin concentration and haematocrit percentage (anaemia) while white blood cell count showed a significant increase in all treatment groups $(p<0.0001)$. The erythrocyte indices like $\mathrm{MCV}$ and $\mathrm{MCH}$ in the exposed groups reduced in a dose-dependent manner but BPA treatment increased $\mathrm{MCHC}$ values $(p>0.05)$. The results of serum biochemistry in BPA exposed fish showed enhanced serum AST, ALT, urea, uric acid and creatinine but decreased serum total protein and albumin. This might be due to the possible disruption of haemopoietic tissue or impairment of liver and kidney function. Based on the results, we conclude that BPA is toxic to Heteropneustes fossilis and its occurrence in the environment may threaten the health of aquatic species. Accordingly, it suggests that haematological and serum biochemical parameters could be effectively used as reflective bioindicators in ecotoxicological studies.
\end{abstract}

\section{INTRODUCTION}

Bisphenol A (BPA), a synthetic chemical substance and extensively used in the production of synthetic plastic polymers, has appeared as a universal pollutant in the aquatic environment (Pal \& Reddy 2018). Because of its widespread use, BPA is released into aquatic environs through sewage and affects the aquatic organisms (Krishnapriya et al. 2017, Faheem et al. 2019, Hassan et al. 2020).

Fish species are very sensitive to aquatic pollution and specific haematological and biochemical biomarkers of fish were demonstrated as direct indicators for assessing the ecological status of an aquatic environment. Many investigations have been conducted using fish as an experimental model for assessing contaminant-induced toxicity (Reddy 2012a,b, Reddy \& Baghel 2012, Reddy \& Rawat 2013, Reddy 2018, Sharma et al. 2019). The affinity between BPA and haemoglobin, as well as erythrocytes, is an important factor in understanding the mechanism of the BPA toxicity (Sangai et al. 2018). Like other toxicants, BPA can exert toxic effects on survival of fish and its accumulation in tissues may affect the metabolic processes like glycolysis, protein and lipid profile of the organism and cause oxidative stress (Javed et al. 2017). The energy requirements of organisms increase in stress condition and biomolecules like glucose, fats, and proteins pull together to meet the energy demand depending on the intensity of stress (Javed et al. 2017).

The study of serum biochemistry reflects the metabolic condition of several biochemical processes and the health status of the organism. A number of researchers used haematological and serum biochemical parameters effectively as reflective bioindicators in ecotoxicological studies (Lavanya et al 2011, Atli et al. 2015, Javed et al. 2017, Narra et al. 2017, Pandit \& Kumari 2018, Ullah et al. 2019). These studies reveal internal alterations before the animal show any external signs of toxic stress (Osman et al. 2010). The in vivo research work of Roy et al. (2011) confirmed the degenerative effects of Bisphenol A on the liver of Heteropneustes fossilis. Hussein \& Eid (2013) found significant disruptive hepatotoxic changes in the liver of mice. Aiswarya \& James (2016) found a significant decrease in $\mathrm{RBC}$, and $\mathrm{Hb}$ concentrations and an increase in WBC content in $H$. fossilis 
exposed to $0.1 \mathrm{~g} / \mathrm{L}$ of BPA for 72 hours. The 28 days treatment with various sublethal concentrations of BPA significantly altered histopathological changes in liver, kidney, and serum biochemical parameters of $H$. fossilis in a dose-dependent manner (Pal \& Reddy 2018). Several ecological stressors may alter serum biochemical parameters in fish. Serum biochemical parameters like AST, ALT, ALP, glucose, urea, creatine, total protein and albumin of fish serum may reflect health status and several biochemical pathways in the metabolism (Yousef et al. 2006, Pal \& Reddy 2018, Nourian et al. 2019).

The present research on alteration in haematological and serum biochemistry has a more extended scope because of its probable advantage in the health diagnosis of the individual. Accordingly, many animal models under different experimental and ecological conditions are conducted to explain the toxic mechanisms of BPA but most of them are from mammalian models. Therefore, the current study assessed the use of a series of biomarkers in $H$. fossilis to measure the health status of fish exposed to different sublethal concentrations of Bisphenol A also and to determine most potentially used parameter as a biomarker of BPA intoxication and fish health status. The haematological and biochemical parameters bioindicators used in this study will provide necessary information on the impact of Bisphenol A (BPA) on fish health. With this perspective, we incorporated haematological and serum biochemical parameters as health indicators.

\section{MATERIALS AND METHODS}

The ethical committee of the University approved the experimental design and all procedures used in the present study.

Materials: Healthy and adult Heteropneustes fossilis were collected from local fishponds and acclimatized to the laboratory backgrounds for 15 days. Bisphenol-A2, 2-Bis (4-hydroxyphenyl) propane (CAS No: 80-05-7. EC No: 201-245-8. Purity: 99.99\%) was obtained from Chemex Chemicals, Mumbai (India).

Experimental design: The after acclimatized fish were categorized into four sets comprising of three replicates containing eight fish (average weight is $35.96 \mathrm{~g}$ ) in each aquarium of 40L capacity. The selection of sublethal concentrations of BPA for this experiment is based on our earlier study (Pal $\&$ Reddy 2018). One control group and three exposed sets containing three concentrations, i.e., $0.714 \mathrm{mg} / \mathrm{L}$ (1/10th), $1.428 \mathrm{mg} / \mathrm{L}(1 / 20 \mathrm{th})$ and $2.142 \mathrm{mg} / \mathrm{L}(1 / 30 \mathrm{th})$ respectively of $\mathrm{LC}_{50}$ value $(7.14 \mathrm{mg} / \mathrm{L})$ (Pal \& Reddy 2018). Both control sets and BPA treated groups were maintained under the same environmental conditions during the experimental period. No fish mortality was recorded during the experimental period. The fish were exposed under normal laboratory conditions for 21 days. Aquarium water along with BPA was entirely substituted once every two days by transferring the fish into freshly prepared BPA solutions. Control and experimental fish received a commercial prawn fish feed (Univar cure, Thane, MH, India).

Collection of blood sample: At the end of experimentation, fish was stopped feeding $24 \mathrm{~h}$ before blood sampling. Blood samples were collected from three fish of each experimental group randomly by puncturing the caudal veins with the help of a heparinized $2 \mathrm{~cm}$ disposable syringe. The blood sample was mixed lightly and used for the estimation of haematological indicators like erythrocyte count (RBC), haemoglobin concentration $(\mathrm{Hb})$, haematocrit (HCT), white blood cell (WBC) count, mean corpuscular volume (MCV), mean corpuscular haemoglobin $(\mathrm{MCH})$ and mean corpuscular haemoglobin concentration (MCHC).

Biochemical analysis: Blood samples were collected by puncturing the caudal region of fish without rinsing the heparinised and stored in clean and dry Eppendorf tubes. The blood samples were allowed for $1 \mathrm{~h}$ to clot at room temperature followed by $30 \mathrm{~min}$ incubation at $4^{\circ} \mathrm{C}$. Serum was obtained by centrifuging the blood samples at $3000 \mathrm{~g}$ for $10 \mathrm{~min}$ at $4^{\circ} \mathrm{C}$. Plasma total proteins, serum albumin, and globulin values were estimated by using a commercial kit obtained from Qualigens Fine Chemicals, Mumbai. Plasma glucose was assessed using a commercially available kit from Diatek, Kolkata. Serum creatinine and uric acid were estimated by the standard procedures given in the commercial kit supplied by Tulip Diagnostics (P) Ltd, Mumbai. All serum values were analysed statistically by Students' $t$-test by Microsoft Excel add-in program. Serum glutamic oxaloacetic transaminase/aspartate aminotransferase (SGOT/AST EC 2.6.1.1) and serum glutamic pyruvic transaminase/alanine aminotransferase/serum glutamic pyruvic transaminase (SGPT/ALT EC 2.6.1.2) were determined by the protocol given by Reitman \& Frankel (1957) using a commercial diagnostic kit (Merck, Germany).

\section{RESULTS}

The sublethal concentrations of BPA did not cause mortality in $H$. fossils during the experimental period. Increased mucus secretion, altered swimming behaviour, and irritability were important changes noticed in some exposed fish during the experimental period. These alterations were severed at the end experimental periods and in fish exposed to higher doses.

Haematological parameters: The mean values of haematological parameters of $H$. fossils exposed to various sublethal concentrations of BPA are given in Table 1. Results revealed that RBCs, HB and HCT were decreased significantly in fish exposed to BPA in all exposed fish in a dose-dependent 
manner when compared to the control group $(p<0.05)$.

The RBC count reduced significantly $(p<0.05)$ in the fish of Group II, III and IV with counts of $1.16 \pm 0.08,1.09 \pm$ $0.07,1.65 \pm 0.94 \pm 0.06$ and $1.31 \pm 0.09$ count $\times 10^{6} \mathrm{~mm}^{3}$ for the control respectively. In contrast, the total WBC count was elevated significantly $(p<0.05)$ in all experimental fish in a dose-dependent manner. Similarly, a significant reduction in $\mathrm{HB} \%$ and $\mathrm{Hct} \%$ were found between the treated and control fish $(p<0.05)$. Haematological indices like MCV, MCH, and $\mathrm{MCHC}$ are vital biomarkers in the diagnosis of anaemia type. The MCV and MCHC are the indicators of erythrocyte size and shape. Their values reflect the normal or abnormal cell division during erythropoiesis. In the present experiment, both MCV and MCH values in $H$. fossilis were increased in all experimental fish compared to the control group $(p>$ $0.05)$. Conversely, MCHC values decreased in exposed fish compared to the control $(p<0.05)$.

Biochemical parameters: The mean values of serum biochemical parameters of $H$. fossilis exposed to various sublethal concentrations of BPA for 21 days are given in Table 2. Significant differences were observed in serum total protein, albumin, globulin, creatine, uric acid, AST and ALT levels of fish exposed to BPA compared to control fish produced lowest values of those variables as compared with those of the control in dose dependent-manner $(p<0.05)$ (Table 2).

Results evidently revealed a significant increase in plasma glucose $(\mathrm{mg} / \mathrm{L})$ concentrations in dose-dependent manner $(p<0.05)$. Conversely, the total plasma protein levels of $H$. fossilis exposed to sublethal concentrations of BPA shown a significant reduction $(p<0.05)$ compared to the control group. Likewise, both albumin, globulin and A: G ratio was also declined expressively in dose-dependent manner $(p<0.05)$. The renal biomarkers of both urea and creatine levels were significantly $(p<0.05)$ increased in all experimental fish exposed to BPA. The activities of alanine aminotransferase (SGPT) and AST (SGOT) were significantly increased $(p<0.05)$ in all BPA exposed fish in dose dependent manner.

\section{DISCUSSION}

Haematological and serum biochemical parameters in fish have proved to be a valuable tool in ecotoxicological

Table 1: Mean values ( \pm standard error) of haematological parameters of $H$. fossilis exposed to BPA.

\begin{tabular}{|lllll|}
\hline Parameter & (Group I Control) & Group II & Group III & Group III \\
\hline RBC $\left(\times 10^{6} / \mathrm{mm}^{3}\right)$ & $1.31 \pm 0.09$ & $1.16 \pm 0.08^{*}$ & $1.09 \pm 0.07^{*}$ & $0.94 \pm 0.06^{* *}$ \\
$\mathrm{WBC}\left(\times 10^{3} / \mathrm{mm}^{3}\right)$ & $188.4 \pm 19.22$ & $202.5 \pm 19.4^{*}$ & $219.7 \pm 22.3^{*}$ & $236.8 \pm 23.8^{*}$ \\
$\mathrm{Hb}(\mathrm{g} / \mathrm{dl})$ & $9.7 \pm 0.9$ & $9.0 \pm 0.8$ & $8.4 \pm 0.7^{*}$ & $7.2 \pm 0.6^{* *}$ \\
$\mathrm{Hct}(\%)$ & $33.2 \pm 3.1$ & $27.6 \pm 2.1^{*}$ & $22.3 \pm 2.4^{*}$ & $16.4 \pm 1.4^{* *}$ \\
$\mathrm{MCV}(\mathrm{fl} / \mathrm{cell})$ & $172.30 \pm 3.7$ & $179.4 \pm 5.2^{*}$ & $186.5 \pm 6.5$ & $194.7 \pm 3.6^{* *}$ \\
$\mathrm{MCH}(\mathrm{pg} / \mathrm{cell})$ & $53.45 \pm 2.6$ & $56.6 \pm 3.1^{*}$ & $63.6 \pm 2.2$ & $69.6 \pm 1.8^{* *}$ \\
$\mathrm{MCHC}(\mathrm{g} / \mathrm{dl})$ & $268.8 \pm 8.2$ & $255.6 \pm 7.7$ & $228.8 \pm 6.8^{*}$ & $198.7 \pm 6.8^{* *}$ \\
\hline
\end{tabular}

Values are characterized as (mean $\pm \mathrm{SE}$ ) of six individual values. *Indicate values, those are significantly different from control and exposure $(p<0.05)$.

Table 2: The serum biochemistry of $H$. fossilis exposed to sublethal concentrations of Bisphenol A.

\begin{tabular}{|c|c|c|c|c|}
\hline Parameter & Group I Control & Group II & Group III & Group III \\
\hline Plasma protein $(\mu \mathrm{g} / \mathrm{mL})$ & $9.77 \pm 0.95$ & $8.34 \pm 0.24 *$ & $6.56 \pm 0.63 *$ & $4.58 \pm 0.61 * *$ \\
\hline Plasma glucose $(\mathrm{mg} / \mathrm{dL})$ & $98.2 \pm 2.11$ & $106.8 \pm 2.87 *$ & $124.5 \pm 3.69 * *$ & $143.5 \pm 4.56 * *$ \\
\hline Albumin (g/dL) & $2.58 \pm 0.08$ & $2.18 \pm 0.06^{*}$ & $2.07 \pm 0.05$ & $1.82 \pm 0.04 * *$ \\
\hline Globulin (g/dL) & $3.23 \pm 0.23$ & $3.08 \pm 0.22$ & $2.84 \pm 0.18^{*}$ & $2.46 \pm 0.2 * *$ \\
\hline A:G ratio & $0.80 \pm 0.02$ & $0.70 \pm 0.01 *$ & $0.72 \pm 0.02 *$ & $0.74 \pm 0.01$ \\
\hline Creatinine (mg/L) & $1.89 \pm 0.02$ & $2.1 \pm 0.03 *$ & $3.4 \pm 0.03 * *$ & $4.9 \pm 0.05 * *$ \\
\hline Uric acid (mg/L) & $5.71 \pm 0.9$ & $9.9 \pm 0.8^{*}$ & $10.7 \pm 0.8 * *$ & $14.6 \pm 1.2 * *$ \\
\hline AST (SGOT) (U/L) & $61.45 \pm 1.1$ & $72.3 \pm 2.5^{*}$ & $86.6 \pm 2.5$ & $119.7 \pm 3.7 * *$ \\
\hline ALT (SGPT) (U/L) & $30.2 \pm 1.5$ & $36.3 \pm 2.5 *$ & $42.3 \pm 3.1$ & $51.4 \pm 3.4 * *$ \\
\hline
\end{tabular}

Means within the same row carrying different *superscripts are significant at $p<0.05$. 
research for evaluating the health status of fish exposed to various pollutants (Saravanan et al. 2011, Krishnapriya et al. 2017, Kumar et al. 2019). BPA intoxication in fish known to induce negative impacts on fish health (Canesi \& Fabbri 2015, Cano-Nicolau et al. 2016, Pal \& Reddy 2018, Wang et al. 2019).

In the present study, the total erythrocyte count, the Ht, and $\mathrm{Hb}$ percentage, and the secondary indices of RBCs of Heteropneustes fossilis exposed to BPA were significantly lower than that of the control group. The reduced RBC count generally also leads to low $\mathrm{Ht}$ and $\mathrm{Hb}$ levels (Javed et al. 2016). The reduction in $\mathrm{RBC}$ count, $\mathrm{Hb}$ and $\mathrm{Ht}$ specifies the anaemic condition of the exposed fish, which could be due to the damage of haemopoietic tissue (kidney/spleen) or inhibition of erythropoiesis. The dose-dependent decrease in haemoglobin concentration in experimental fish might be the consequence of injury or cellular damage or suppression of haemopoietic tissue of the fish (Kumar \& Banerjee 2016). The obvious haemorrhage or haemolysis caused microcytic anaemia, as regenerating small and immature erythrocytes formed in response to BPA stress, constitute the majority of cells in outer circulation (Clauss et al. 2008). The anaemia in experimental fish might be due to decreased erythropoiesis caused by the intoxication of BPA on haematopoietic tissues (kidney/spleen). The results of the present study are in agreement with the result of Keum et al. (2005) in Korean rockfish, Sebastes schlegeli, Aiswarya \& James (2016) in $H$. fossilis, and Yaghoobi et al. (2017) in yellowfin seabream (Acanthopagrus latus) and Krishnapriya et al. (2017) in Labeo rohita, exposed to various sublethal concentrations of Bisphenol A. The reduction in RBCs, Ht and $\mathrm{Hb}$ levels in BPA exposed $H$. fossilis indicate hypochromic microcytic anaemia (Narra et al. 2017) which might be due to both the inhibition of haemosynthesis, erythropoiesis or osmoregulatory dysfunction or rapid erythrocyte destruction in the haematopoietic organ (Narra et al. 2017, Kumar Maurya et al. 2019, Yonar et al 2020). In the same way, the substantial reduction in Hct value indicates the anaemic condition of the fish due to BPA toxicity, which is a common reaction in fish under stress conditions (Krishnapriya et al. 2017). The reduction in secondary indices of RBC specifies the shrinkage of RBCs due to the toxic stress prompted by BPA. The significant decrease in $\mathrm{Hb}$ percentage may perhaps lead to a reduction in MCHC value (Sarma 1990). The present experiment also exposed that the sublethal concentrations of the BPA may affect the $\mathrm{Hb}$ synthesis in $H$. fossilis resulting in a significant decrease of $\mathrm{MCHC}$ value. The higher values of $\mathrm{MCV}$ and $\mathrm{MCH}$ in the present study indicate the macrocytic condition and low values as microcytic conditions (Javed et al. 2016). In the present study, BPA exposure induced macrocytic anaemia as MCV values showed higher levels as compared to the control fish. The macrocytic anaemia occurs when a cell is unable to produce an adequate amount of DNA quickly as compared to cell growth (Javed et al. 2016). Our results are in agreement with the findings of Aiswarya \& James (2016) and Yaghoobi et al (2017). The study of Keum et al. (2005) has demonstrated that BPA can induce adverse impacts on haematological parameters and serum biochemical parameters in the Korean rockfish, Sebastes schlegeli. The results of Krishnapriya et al. (2017) have shown that BPA exposure modifies the haematological and biochemical parameters in fish, L. rohita. Similarly, the study of Yaghoobi et al. (2017) also showed an inverse correlation of BPA with $\mathrm{RBC}, \mathrm{Ht}, \mathrm{Hb}$, and secondary indices in yellowfin seabream (Acanthopagrus latus). Kumar Mourya et al. (2019) found a significant reduction in the $\mathrm{RBC}$ count, $\mathrm{Hb}$ and Hct percentage in $H$. fossilis exposed to the industrial wastewater at various concentrations.

Leucocytes play a major role in the non-specific immunity of the fish defence system. Assessment of total leucocyte count (TLC) is acknowledged as an important tool for assessing fish health conditions (Maceda-Veiga et al. 2010). WBCs mainly involve in nonspecific immunity of fish. In the present experiment, the BPA intoxication caused a significant increase in the total WBC count of experimental fish in a dose-dependent manner, which might be a general immune response and a protective reaction to BPA stress. Another possible reason for an increase in total WBCs count is due to the BPA induced toxic stress which might stimulate the leucocytosis/lymphopoiesis from lymphomyeloid tissue for effective defence against BPA toxicity. The higher values of total WBC might be due to increasing lymphopoiesis and/or higher release of lymphocytes from lymphomyeloid tissue. Such response in fish happens due to tissue damage by the accumulation of toxic materials, which consequently stimulated the non-specific immune system to produce more number of leucocytes. The increase in total leucocytes count in the present experiment may be endorsed to an adaptive higher immune response to protect the fish effectively from the BPA induced stress. Our results are in agreement with the results of Kumar \& Banerjee (2016) in Clarias batrachus exposed to sublethal concentrations of arsenic. The reduction in erythrocyte count and $\mathrm{Hb}$ concentration along with increased WBC count were also observed when the same fish was exposed to different concentrations of BPA (Aiswarya \& James 2016 and Pal \& Reddy 2018). Srinivasa Rao et al. (2018) also found decreased values of RBC, Hb, Hct, and increased values of WBC in the fish Ctenopharyngodon idella exposed to lethal and sublethal concentrations of synthetic pyrethroid deltamethrin and $11 \%$ Decis.

Serum biochemistry in fish is extensively used in the assessment of dietary status, health status, and the compe- 
tence of fish for adaptation to the external environment (Firat et al. 2011, Acharya \& Mohanty 2014, Sharma et al. 2017, Pandit \& Rani 2019). In the present experiment, all the serum biochemical variables in fish were significantly affected by BPA treatment. In the present study, BPA treatment caused the elevation of glucose level and inhibition of total serum proteins in a dose-dependent manner in H. fossilis. The increase in plasma glucose level reflects the enhanced glycogenolysis and inhibited glycolytic pathway in BPA treated fish. Our outcomes are analogous with those of Pal \& Reddy (2018), Sisodia et al. (2018), in BPA exposed H. fossilis and El-Sayed et al. (2007) in Nile tilapia exposed to deltamethrin. The elevated levels of glucose in the present study might be due to the stress caused by BPA, which enhanced the synthesis of adrenocorticotropic hormone (ACTH), glucagon, and decline in the synthesis of insulin (El-Sayed et al. 2007, Provvisiero et al. 2016). As a result, glycogen from hepatic tissue is rapidly converted into glucose and entered into blood circulation. Accordingly, the clarification of this BPA induced temporary stress effect in all experimental groups of $H$. fossilis may be endorsed to either reduction in the synthesis of the above-cited hormones or to higher energy demand, that stimulates the use and consumption of glucose (El-Sayed et al. 2007).

The protein synthesis is of great indicative importance as it is involved in the synthesis of enzymes, hormones and antibodies. Therefore, the effects of BPA on plasma total protein levels of $H$. fossilis have taken into consideration to assess the toxic effects of BPA. Serum total protein, albumin, and globulin experiments in fish are used to monitor the health status, liver disorder and impaired kidney function (Banaee 2013). In the present study, the values of serum total protein, albumin, and globulin were reduced significantly in fish exposed to BPA. The reduction in total serum protein, albumin, and globulin contents may be due to undernourishment and chronic liver disease as in rainbow trout (Oncorhynchus mykiss) exposed to diazinon (Banaee et al. 2011). Other researchers also found in the reduction of serum total protein, albumin and globulin in the fish exposed to various pollutants (Bhanu \& Deepak 2015, Javed \& Usmani 2015, Javed et al. 2017, Banaee et al. 2019). The reduction in the serum total protein concentration is accredited to low synthesis or increased loss of plasma proteins (hypoproteinemia) as in yellowfin sea bream, Acanthopagrus latus (Hedayati et al. 2011). Loss of protein, both albumin and globulin, occurs with haemorrhage and external injuries. The decrease of total serum protein, albumin, and globulin and albumin/ globulin ratio particularly at the higher BPA doses reflects the hepatic dysfunction and immunosuppressive effect of the BPA. The decrease in total protein content of exposed fish perhaps due to either ceased metabolism or use it to create new cells or enzymes to reduce the stress. Our results are in agreement with the findings of El-Sayed et al. (2007) in Nile tilapia, Oreochromis niloticus exposed deltamethrin and Hedayati et al. (2011) in yellowfin sea bream, Acanthopagrus latus exposed to mercury chloride. The decrease of total serum protein content in the present experiment could be due to the conversion of blood and structural proteins to meet the higher energy demands on exposure to different BPA concentrations. However, some researchers endorsed to liver disorder or/and renal excretion for the reduction of serum protein in fish (Mutlu et al. 2015). The reduction in serum total protein, albumin and globulin may perhaps also be due to a higher haemodilution under the toxic stress of BPA (Kumar et al. 2011).

It is observed that BPA exposure significantly increased serum AST, ALT, urea and creatinine values. The obtained outcomes perhaps due to the toxic effects of BPA, which is known to induce several pathological processes in different fish organs (Pal \& Reddy 2018, Manisha Sisodia et al. 2018, Faheem et al, 2019). It is well-known fact that AST, and ALT, are often used as a diagnostic tool to identify the damage in various tissues caused by pollutants (McGill 2016, Lala \& Minter 2018). The higher AST and ALT activities point out the higher rate of transamination of proteins and subsequent consumption of free amino acids in the glycogenic pathway. Pal \& Reddy (2018) and Manisha Sisodia et al. (2018) have given evidence that even a moderately elevated level of AST in serum is linked with liver damage. Similarly, urea and creatinine are traditional diagnostic tools for renal structural integrity and function. The reactive oxygen species (ROS) formed during BPA metabolism in can enhance the permeability of hepatic cells which results in leakage of AST, and ALT, enzymes into the blood circulation (Hamed \& Abdel-Tawwab 2017, Pal \& Reddy 2018, Sisodia et al. 2018, Mahdavinia et al. 2019, Faheem et al. 2019). Faheem et al. (2019) reported a similar increase in serum AST and ALT activities in Catla catla exposed to BPA. Alterations in AST and ALT activities directly point out cellular damage in hepatic tissue (Pal \& Reddy 2018, Sisodia et al. 2018).

The values of serum creatinine and uric acid in vertebrates reflect the status of renal health, function, and muscle health and purine metabolism (Hamed \& Tawwab 2017). Glomerulus damage, impair metabolism of carbohydrates and increased damage of muscle tissue may cause increased creatinine levels in the blood (Hadi et al. 2009). In the present study, a significant increase was recorded in serum creatinine and uric acid level of BPA exposed fish specifies that BPA affects muscle and purine (nucleic acid) metabolism as in Channa punctatus exposed to industrial effluent (Javed et al. 2016). This increase may also be due to the damage of 
renal tubules. Degeneration and necrosis of glomerulus and a decrease in haematopoietic tissue in Catla catla after BPA exposure was reported by Faheem et al. (2019). This decrease in haematopoietic tissue may be a cause of an increase in serum uric acid. Similar results were reported in Nile tilapia (Oreochromis niloticus) exposed to copper sulphate (Mutlu et al. (2015), BPA exposed Nile tilapia, Oreochromis niloticus (Abdel-Tawwab \& Hamed 2018) and in Catla catla (Faheem et al. 2019). The toxic effect of BPA in the kidney is endorsed to its role in declining glomerular filtration rate (GFR) that is specified by a substantial increase in serum creatinine (Abdelkhalek et al. 2017). Faheem et al. (2019) observed a significant increase in serum urea and creatinine after BPA treatment in Catla catla. Jyothi \& Narayan (2000) found a significant elevation in serum urea and creatinine after pesticide intoxication in a freshwater catfish, Clarias batrachus. Hamed et al. (2019) found a significant reduction in RBC's count, $\mathrm{Hb}, \mathrm{Ht}, \mathrm{MCHC}$, platelets, and WBC's count and increase of creatinine, uric acid, AST, ALT, ALP, glucose, cholesterol, total protein, albumin, globulin, and A/G ratio in Nile tilapia (Oreochromis niloticus) exposed to microplastics for 15 days. The results confirm that BPA caused functional and structural damage in the kidney, which was reflected in the increased urea and uric acid levels with impairment in their excretion.

\section{CONCLUSIONS}

The current study thus confirmed that haematological parameters are very responsive parameters for evaluating toxic responses of the fish following exposure to BPA. BPA intoxication reveals the anaemic condition in fish species. We believe that alterations in haematological indices and serum biochemistry may be a protective mechanism against BPA toxicity. Overall, the present study offers supplementary shreds of evidences for the usage of serum biomarkers in assessing the health of fish. The study also confirms the appropriateness of $H$. fossilis as experimental species and underlining the need for additional research to validate the presence of xenobiotics or other environmental toxins.

\section{REFERENCES}

Abdelkhalek, N.K., Eissa, I.A., Ahmed, E., Kilany, O.E., El-Adl, M., Dawood, M.A., Hassan, A.M. and Abdel-Daim, M.M. 2017. Protective role of dietary Spirulina platensis against diazinon-induced oxidative damage in Nile tilapia, Oreochromis niloticus. Environmental Toxicology and Pharmacology, 54: 99-104.

Abdel-Tawwab, M. and Hamed, H.S. 2018. Effect of bisphenol A toxicity on growth performance, biochemical variables, and oxidative stress biomarkers of Nile tilapia, Oreochromis niloticus (L.). Journal of Applied Ichthyology, 34(5): 1117-1125.

Acharya, G. and Mohanty, P.K. 2014. Haematological and serum biochemical parameters in different sexes of walking catfish, Clarias batrachus
(Linnaeus, 1758). International Journal of Science and Research, 3(8): 1914-1917.

Aiswarya, K.S. and James, R. 2016. Effect of Bisphenol A on certain haematological parameters of Heteropneustes fossilis, Bloch. International Journal of Emerging Trends in Science and Technology, 3(08): 4493-4497.

Atli, G., Ariyurek, S.Y., Kanak, E.G. and Canli, M. 2015.Alterations in the serum biomarkers belonging to different metabolic systems of fish (Oreochromis niloticus) after $\mathrm{Cd}$ and $\mathrm{Pb}$ exposures. Environmental Toxicology and Pharmacology, 40(2): 508-515.

Banaee, M. 2013. Physiological dysfunction in fish after insecticides exposure. In: Insecticides-Development of Safer and More Effective Technologies. IntechOpen.

Banaee, M., Sureda, A., Mirvaghefi, A.R. and Ahmadi, K. 2011. Effects of diazinon on biochemical parameters of blood in rainbow trout (Oncorhynchus mykiss). Pesticide Biochemistry and Physiology, 99(1): 1-6.

Banaee, M., Tahery, S., Nematdoost Haghi, B., Shahafve, S. and Vaziriyan, M. 2019. Blood biochemical changes in common carp (Cyprinus carpio) upon co-exposure to titanium dioxide nanoparticles and paraquat. Iranian Journal of Fisheries Sciences, 18(2): 242-255.

Bhanu, A.P. and Deepak, M. 2015. Impact of cypermethrin on biochemical aspects of clinical importance in the blood of freshwater fish Cyprinus carpio. Journal of Entomology and Zoology Studies, 3: 126-128.

Canesi, L. and Fabbri, E. 2015. Environmental effects of BPA: Focus on aquatic species. Dose-Response, 13(3): 1559325815598304.

Cano-Nicolau, J., Vaillant, C., Pellegrini, E., Charlier, T.D., Kah, O. and Coumailleau, P. 2016. Estrogenic effects of several BPA analogs in the developing zebrafish brain. Frontiers in Neuroscience, 10: 112.

Clauss, T.M., Dove, A.D. and Arnold, J.E. 2008. Hematologic disorders of fish. Veterinary Clinics of North America: Exotic Animal Practice, 11(3): 445-462.

El-Sayed, Y.S., Saad, T.T. and El-Bahr, S.M. 2007. Acute intoxication of deltamethrin in monosex Nile tilapia, Oreochromis niloticus with special reference to the clinical, biochemical and haematological effects. Environmental Toxicology and Pharmacology, 24(3): 212-217.

Faheem, M., Khaliq, S. and Lone, K.P. 2019. Effect of Bisphenol-A on serum biochemistry and liver function in the freshwater fish, Catla catla. Pakistan Veterinary Journal, 39(1): 71-75.

Fırat, Ö., Cogun, H.Y., Yüzereroğlu, T.A., Gök, G., Fırat, Ö., Kargin, F. and Kötemen, Y. 2011. A comparative study on the effects of a pesticide (cypermethrin) and two metals (copper, lead) to serum biochemistry of Nile tilapia, Oreochromis niloticus. Fish Physiology and Biochemistry, 37(3): 657-666.

Hadi, A., Shokr, A. and Alwan, S. 2009. Effects of aluminum on the biochemical parameters of fresh waterfish Tilapia zillii. Journal of Science and its Applications, 3(1): 33-41.

Hamed, H.S. and Abdel-Tawwab, M. 2017. Ameliorative effect of propolis supplementation on alleviating bisphenol-A toxicity: Growth performance, biochemical variables, and oxidative stress biomarkers of Nile tilapia, Oreochromis niloticus (L.) fingerlings. Comparative Biochemistry and Physiology Part C: Toxicology \& Pharmacology, 202: 63-69.

Hamed, M., Soliman, H.A., Osman, A.G. and Sayed, A.E.D.H. 2019. Assessment the effect of exposure to microplastics in Nile Tilapia (Oreochromis niloticus) early juvenile: I. Blood biomarkers. Chemosphere, 228: 345-350.

Hassan, S., Ali, R., Shah, D., Sajjad, N. and Qadir, J. 2020. Bisphenol A and phthalates exhibit similar toxicogenomics and health effects. In: Handbook of Research on Environmental and Human Health Impacts of Plastic Pollution (pp. 263-287). IGI Global.

Hedayati, A., Safahieh, A., Savari, A., Movahedinia, A., Zare, P. and Bagheri, T. 2011. Serum biochemical change induced by in vitro sub chronic 
mercury chloride in yellowfin sea bream (Acanthopagrus latus). Iranica Journal of Energy and Environment, 2(3): 208-214.

Hussein, R.M. and Eid, J.I. 2013. Pathological mechanisms of liver injury caused by oral administration of bisphenol A. Life Science Journal, 10(1): 663.

Javed, M. and Usmani, N. 2015. Stress response of biomolecules (carbohydrate, protein and lipid profiles) in fish Channa punctatus inhabiting river polluted by Thermal Power Plant effluent. Saudi Journal of Biological Sciences, 22(2): 237-242.

Javed, M., Ahmad, I., Ahmad, A., Usmani, N. and Ahmad, M. 2016. Studies on the alterations in haematological indices, micronuclei induction and pathological marker enzyme activities in Channa punctatus (spotted snakehead) perciformes, channidae exposed to thermal power plant effluent. SpringerPlus, 5(1): 761.

Javed, M., Ahmad, M.I., Usmani, N. and Ahmad, M. 2017. Multiple biomarker responses (serum biochemistry, oxidative stress, genotoxicity and histopathology) in Channa punctatus exposed to heavy metal loaded wastewater. Scientific Reports, 7(1): 1675.

Jyothi, B. and Narayan, G. 2000. Pesticide induced alterations of non-protein nitrogenous constituents in the serum of a freshwater catfish, Clarias batrachus (Linn.). Indian Journal of Experimental Biology, 38(10): 1058-61.

Keum, Y.H., Jee, J.H., Lee, O.H., Park, S.I. and Kang, J.C. 2005. In vivo effects of bisphenol A exposure on haematological parameters in Korean rockfish, Sebastes schlegeli. Journal of Fish Pathology, 18(3): 293-300.

Krishnapriya, K., Shobana, G., Narmadha, S., Ramesh, M. and Maruthappan, V. 2017. Sublethal concentration of bisphenol A induces haematological and biochemical responses in an Indian major carp Labeo rohita. Ecohydrology and Hydrobiology, 17(4): 306-313.

Kumar Maurya, P., Malik, D.S., Kumar Yadav, K., Gupta, N. and Kumar, S. 2019. Haematological and histological changes in fish Heteropneustes fossilis exposed to pesticides from industrial wastewater. Human and Ecological Risk Assessment, 25(5): 1251-1278.

Kumar, A., Ahirwal, S.K., Bhatt, R. and Singh, I.J. 2019. Certain haematological and biochemical changes in blood of rohu (Labeo rohita) in relation to sex, reproductive status and environmental factors. Journal of Entomology and Zoology Studies, 7(3): 1484-1490.

Kumar, N., Prabhu, P.A.J., Pal, A.K., Remya, S., Aklakur, M., Rana, R.S., Gupta, S., Raman, R.P. and Jadhao, S.B. 2011. Anti-oxidative and immuno-haematological status of Tilapia (Oreochromis mossambicus) during acute toxicity test of endosulfan. Pesticide Biochemistry and Physiology, 99(1): 45-52.

Kumar, R. and Banerjee, T.K. 2016. Arsenic induced haematological and biochemical responses in nutritionally important catfish Clarias batrachus (L.). Toxicology Reports, 3:148-152.

Lala, V. and Minter, D.A. 2018. Liver Function Tests. In: Stat Pearls. Stat Pearls Publishing.

Lavanya, S., Ramesh, M., Kavitha, C. and Malarvizhi, A. 2011. Hematological, biochemical and ionoregulatory responses of Indian major carp Catla catla during chronic sublethal exposure to inorganic arsenic. Chemosphere, 82(7): 977-985.

Maceda-Veiga, A., Monroy, M., Viscor, G. and De Sostoa, A. 2010. Changes in non-specific biomarkers in the Mediterranean barbel (Barbus meridionalis) exposed to sewage effluents in a Mediterranean stream (Catalonia, NE Spain). Aquatic Toxicology, 100(3): 229-237.

Mahdavinia, M., Alizadeh, S., Vanani, A.R., Dehghani, M.A., Shirani, M., Alipour, M., Shahmohammadi, H.A. and Asl, S.R. 2019. Effects of quercetin on bisphenol A-induced mitochondrial toxicity in rat liver. Iranian Journal of Basic Medical Sciences, 22(5): 499.

McGill, M.R. 2016. The past and present of serum aminotransferases and the future of liver injury biomarkers. EXCLI Journal, 15: 817.
Mutlu, E., Aydın, S. and Kutlu, B. 2015. Alterations of growth performance and blood chemistry in Nile tilapia (Oreochromis niloticus) affected by copper sulfate in long-term exposure. Turkish Journal of Fisheries and Aquatic Sciences, 15(3): 481-488.

Narra, M.R. 2017. Haematological and immune upshots in Clarias batrachus exposed to dimethoate and defying response of dietary ascorbic acid. Chemosphere, 168: 988-995.

Narra, M.R., Rajender, K., Reddy, R.R., Murty, U.S. and Begum, G. 2017. Insecticides induced stress response and recuperation in fish: Biomarkers in blood and tissues related to oxidative damage. Chemosphere, 168: 350-357.

Nourian, K., Baghshani, H. and Shahsavani, D. 2019. The Effect of Vitamin C on Lead-induced Plasma Biochemical Alterations in Fish, Cyprinus carpio. Iranian Journal of Toxicology, 13(2): 25-29.

Osman, A.G., Koutb, M. and Sayed, A.E.D.H. 2010. Use of haematological parameters to assess the efficiency of quince (Cydonia oblonga Miller) leaf extract in alleviation of the effect of ultraviolet - A radiation on African catfish Clarias gariepinus (Burchell, 1822). Journal of Photochemistry and Photobiology B: Biology, 99(1): 1-8.

Pal, S. and Reddy, P.B. 2018. Bisphenol A induced histopathological and biochemical alterations in the liver and kidney of stinging cat fish Heteropneustes fossilis. Trends in fisheries Research, 7(1): 67-74.

Pandit, D.N. and Kumari, V. 2018. Lead Induced Alterations in Serum Biochemical Features of an Indian Air-Breathing Catfish, Clarias batrachus (Linnaeus). Int. J. Chem. Sci., 16(4): 294.

Pandit, D.N. and Rani, U. 2019.Toxicity of tricyclazole on certain serum biochemical markers of an Indian paddy-field fish, Channa punctatus (Bloch). International Journal of Fisheries and Aquatic Studies, 7(6): 246-250.

Provvisiero, D., Pivonello, C., Muscogiuri, G., Negri, M., de Angelis, C., Simeoli, C., Pivonello, R. and Colao, A. 2016. Influence of bisphenol A on type 2 diabetes mellitus. International Journal of Environmental Research and Public Health, 13(10): 989.

Reddy, P.B. 2012a. Histopathological studies as potential and direct biomarkers of pollution. Trends in Life sciences, 1(1): 27-31.

Reddy, P.B. 2012b. Evaluation of potential biomarkers for effluent induced hepatotoxicity. International Journal on Applied Bioengineering, 6(2): 22-27.

Reddy, P.B. 2018. Study on the toxic effects of wastewater in catfish (Heteropneustes fossilis). Life Sciences International Research Journal, 5(2): 165-174

Reddy, P.B. and Baghel, B.S. 2012. Impact of Industrial wastewater on the Chambal River and Biomarker responses in fish due to pollution at Nagda. MP India. DAV International Journal Sciences, 1(1): 86-91.

Reddy, P.B. and Rawat, S.S. 2013. Assessment of aquatic pollution using histopathology in fish as a protocol. International Research Journal of Environment Sciences, 2(8): 79-82.

Reitman, S. and Frankel, S. 1957. A colorimetric method for the determination of serum glutamic oxaloacetic and glutamic transaminases. American Journal of Clinical Pathology, 28: 56-63.

Roy, S., Kalita, C.J. and Mazumdar, M. 2011. Histopathlogical effects of Bisphenol A on liver of Heteropneustes fossilis (Bloch). The Ecoscan, 1: 187-190.

Sangai, N.P., Patel, C.N. and Pandya, H.A. 2018. Ameliorative effects of quercetin against bisphenol A-caused oxidative stress in human erythrocytes: an in vitro and in silico study. Toxicology Research, 7(6): 1091-1099.

Saravanan, M., Kumar, K.P. and Ramesh, M. 2011. Haematological and biochemical responses of freshwater teleost fish Cyprinus carpio (Actinopterygii: Cypriniformes) during acute and chronic sublethal exposure to lindane. Pesticide Biochemistry and Physiology, 100(3): 206-211. 
Sarma, P.R. 1990. Red cell indices. In: Clinical Methods: The History, Physical, and Laboratory Examinations. 3rd edition. Butterworths.

Sharma, N.K., Akhtar, M.S., Pandey, N.N., Singh, R. and Singh, A.K. 2017. Sex specific seasonal variation in haematological and serum biochemical indices of Barilius bendelisis from Central Himalaya, India. Proceedings of the National Academy of Sciences, India Section B: Biological Sciences, 87(4): 1185-1197.

Sharma, P., Chadha, P. and Saini, H.S. 2019. Tetrabromobisphenol A induced oxidative stress and genotoxicity in fish Channa punctatus. Drug and Chemical Toxicology, 42(6): 559-564.

Sisodia, Manisha, Khare, Meena and Kanhere, R.R. 2018. Biochemical effects of Bisphenol A (BPA) in Asian stinging fish Heteropneustes fossilis. International Journal of Researches in Biosciences, Agriculture and Technology, (VII)(1): 10-18.

Srinivasa Rao, G., Naik, K.B., Satyanarayana, S. and Rao, N.G. 2018. Haematological changes induced by the deltamethrin a synthetic pyrethroid technical grade and $11 \%$ EC (Decis) in the fish Ctenopharyngodon idella (Valenciennes). Journal of Innovations in Pharmaceutical and Biological Sciences, 5: 128-134.
Ullah, S., Li, Z., Arifeen, M.Z.U., Khan, S.U. and Fahad, S. 2019. Multiple biomarkers based appraisal of deltamethrin-induced toxicity in silver carp (Hypophthalmichthys molitrix). Chemosphere, 214: 519-533.

Wang, Q., Yang, H., Yang, M., Yu, Y., Yan, M., Zhou, L., Liu, X., Xiao, S., Yang, Y., Wang, Y. and Zheng, L. 2019. Toxic effects of bisphenol A on goldfish gonad development and the possible pathway of BPA disturbance in female and male fish reproduction. Chemosphere, 221: 235-245.

Yaghoobi, Z., Safahieh, A., Ronagh, M.T., Movahedinia, A. and Mousavi, S.M. 2017. Hematological changes in yellowfin seabream (Acanthopagrus latus) following chronic exposure to bisphenol A. Comparative Clinical Pathology, 26(6): 1305-1313.

Yonar, S.M., Yonar, M.E., Pala, A., Sağlam, N. and Sakin, F. 2020. Effect of trichlorfon on some haematological and biochemical changes in Cyprinus carpio: The ameliorative effect of lycopene. Aquaculture Reports, 16: 100246.

Yousef, M.I., Awad, T.I. and Mohamed, E.H. 2006. Deltamethrin-induced oxidative damage and biochemical alterations in rat and its attenuation by Vitamin E. Toxicology, 227(3): 240-247. 